\title{
Sanguinarine-Mediated Sensitization of Cervical Cancer SiHa Cells to TRAIL
}

\author{
Eric Romney¹, Whitney Wilson ${ }^{2}$, Justin Chen ${ }^{3}$, Trung Nguyen ${ }^{3}$, Omar Jawhar ${ }^{3}$, Aniket Mody3, \\ Shaleen Korch ${ }^{4}$, Vinay J Nagaraj ${ }^{*}$
}

${ }^{1}$ Corpus Christi Medical Center, Corpus Christi, Texas, USA

${ }^{2}$ John C Lincoln Health Network, Phoenix, Arizona, USA

${ }^{3}$ Arizona College of Osteopathic Medicine, Midwestern University, Glendale, Arizona, USA

${ }^{4}$ Department of Pharmacology, Midwestern University, Glendale, Arizona, USA

${ }^{5}$ Department of Biochemistry, Midwestern University, Glendale, Arizona, USA

Email: *skorch@midwestern.edu, ^nvinay@midwestern.edu

How to cite this paper: Romney, E., Wilson, W., Chen, J., Nguyen, T., Jawhar, O., Mody, A., Korch, S. and Nagaraj, V.J. (2017) Sanguinarine-Mediated Sensitization of Cervical Cancer SiHa Cells to TRAIL. Journal of Cancer Therapy, 8, 624-635.

https://doi.org/10.4236/jct.2017.86053

Received: May 22, 2017

Accepted: June 27, 2017

Published: June 30, 2017

Copyright (C) 2017 by authors and Scientific Research Publishing Inc. This work is licensed under the Creative Commons Attribution International License (CC BY 4.0).

http://creativecommons.org/licenses/by/4.0/

\begin{abstract}
Introduction: Cervical cancer is primarily caused by the human papilloma virus (HPV), which transforms normal cervical cells into cancerous cells that are highly resistant to radiation and chemotherapy. Induction of apoptosis in transformed cells is a key strategy in successfully treating HPV-induced cervical cancer. TRAIL (tumor necrosis factor related apoptosis-inducing ligand) has been shown to selectively induce apoptosis in cancer cells by binding to death receptors and activating extrinsic pathways for apoptosis. However, certain cervical cancers-such as the cultured cell line $\mathrm{SiHa}$-are remarkably resistant to TRAIL. In this study, SiHa cells were sensitized to TRAIL by using sanguinarine-derived from the plant Sanguinaria Canadensis-which is known to induce oxidative stress and lead to the upregulation of receptors for TRAIL. Methods: Cultured SiHa cells were exposed to sub-lethal doses of sanguinarine in combination with TRAIL. Cell viability changes as well as the production of reactive oxygen species (ROS) were assessed. The induction of apoptosis was investigated by assays for caspase activation. Flow cytometry was performed to analyze expression of death receptors 4/5. Results: Treatment of SiHa cells with a combination of sanguinarine and TRAIL led to a significant reduction in cell viability. Significant increase in ROS was observed and caspase activation assays confirmed the induction of apoptosis. Conclusions: The observed synergistic effect of sanguinarine and TRAIL on SiHa cells is promising for the treatment of cervical, and possibly other, HPV-induced cancers. Oxidative stress caused by sanguinarine seems to play a central role in this synergy. The precise link between reactive oxygen species and the possible upregulation of death receptors needs further investigation. This knowledge will enable us to devise more effective treatments for those
\end{abstract}


who suffer from this devastating disease.

\section{Keywords}

Cervical Cancer SiHa Cells, Human Papilloma Virus (HPV), Sanguinarine, TRAIL (Tumor Necrosis Factor Related Apoptosis-Inducing Ligand)

\section{Introduction}

An estimated 12,900 women in the United States were diagnosed with cervical cancer with approximately 4100 deaths in 2015 [1] [2]. Worldwide, cervical cancer was the fourth most commonly diagnosed cancer in women with an estimated 236,000 deaths in 2013 [3]. Despite lowering incidence rates with successful screening programs in many developed countries, cervical cancer continues to remain the second most deadly cancer for young women ages 20 - 39 in the United States, with minority women having a disproportionately higher incidence and mortality [2].

Human Papilloma Virus (HPV) infection has been detected in over 99.7\% of all cervical cancers and is known to be directly responsible for the transformation of normal cervical cells [4]. HPV is a double-stranded DNA virus with over 170 types that infect human epithelial cells. HPV strains can be split into low-risk types which typically cause genital warts, and high-risk types that lead to cervical cancer. Of the high-risk types, HPV 16 and 18 are the most prevalent, representing $50 \%$ and $20 \%$ of cervical cancers respectively [5]. In addition, HPV 16 and 18 strains are being recognized as an important cause of head and neck cancers. These cancers are highly aggressive and generally resistant to radiation, chemotherapy and surgical interventions. Although screening and vaccination have increased both early diagnosis and prevention of cervical cancer, widespread infections combined with poor compliance to preventative recommendations have necessitated the development of novel chemotherapeutic strategies.

As with most squamous cell epithelial carcinomas, the initial therapy for non-invasive cervical cancer is surgical resection [6]. This approach, however, can fail to remove non-dysplastic tissue infected with HPV and thus has a high potential for relapse [6] [7]. For women diagnosed with locally advanced disease, radiation therapy with chemotherapy was found to be superior to radiation therapy alone [8]. The current chemotherapy agents of choice are platinum based compounds combined with another agent; examples include cisplatin, with or without 5-fluorouracil (5-FU), or carboplatin combined with paclitaxel [8] [9] [10] [11]. Some of the major drawbacks of current chemotherapy regimens include dose-dependent side-effects due to non-specific targeting of all rapidly dividing cells in the body as well the development of drug resistance.

One approach has been to study how the immune system is capable of self-regulation and elimination of cancer while sparing adjacent healthy noncancerous cells. Tumor necrosis factor-related apoptosis-inducing ligand (TRA- 
IL), a small endogenous cytokine, has been shown to induce apoptosis selectively in some cancer cells [12] [13] [14]. TRAIL is a membrane bound or soluble ligand that can trigger apoptosis through the binding and cross-linking of death receptors (DR): DR4 and DR5 [15] [16]. Binding of these receptors results in the activation of extrinsic pathways leading to caspase-dependent programmed cell death [12] [15] [17] [18]. Despite promising preclinical studies, results from clinical trials of recombinant TRAIL have remained inconclusive [19] [20] [21]. Further research to effectively utilize the chemotherapeutic potential of TRAIL is of particular interest.

The SiHa cell line, a human grade II cervix squamous cell carcinoma, was previously found resistant to TRAIL [12]. Previous efforts to sensitize SiHa cells to TRAIL have shown mixed results. Specifically, siRNA against HPV E6/E7 has been shown to be ineffective and resulted in senescence rather than promoting apoptosis, whereas proteasome inhibitors were somewhat effective [12] [17]. Recently, sanguinarine, a benzophenanthridine alkaloid derived from the root of Sanguinaria Canadensis, has shown potential for sensitizing human gastric adenocarcinoma (AGS) and human breast adenocarcinoma (MDA-231) to TRAIL [22] [23]. As a botanical compound, sanguinarine is multifaceted with known antimicrobial, anti-inflammatory, antioxidant and anti-oncogenic properties [22] [24] [25]. Its ability to induce apoptosis in cancer cells, while leaving normal cells relatively unaffected, is very promising [23] [25] [26]. In this study, we investigate the ability of sanguinarine to sensitize SiHa cells to TRAIL and the molecular pathways that are involved.

\section{Materials and Methods}

\subsection{Cell Line and Cell Culture}

The human grade II cervix squamous cell carcinoma cell line, SiHa, was purchased from American Type Culture Collection (Manassas, VA). Cells were cultured in DMEM supplemented with 10\% FBS and 0.2\% penicillin-streptomycin (Cambrex Bio Science, Walkersville MD) in controlled conditions with a temperature of $37^{\circ} \mathrm{C}$, relative humidity of $95 \%$ and $5 \% \mathrm{CO}_{2}$. Cultures were also supplemented with $0.1 \%$ Normocin (Invivogen, San Diego, CA) to provide additional protection against possible mycoplasma and fungi contamination. All drug treatments and experiments were performed on cells in the logarithmic growth phase (a cell density of approximately $50 \%-70 \%$ confluency).

\subsection{Cell Treatments and Assessment of Cell Viability}

SiHa cells in a tissue-culture flask were washed with PBS, harvested by trypsinization, counted with a hemocytometer, and subsequently seeded on to a 96-well plate at a density of 5000 cells per well. After 24 hours of seeding, cells were exposed to varying concentrations of sanguinarine chloride (Tocris Bioscience, Bristol, UK), human recombinant-TRAIL (EMD Millipore, Temecula, CA), or combinations of the two drugs for different durations.

Cell viability was measured using the XTT Cell Proliferation Assay Kit (Tre- 
vigen, Gaithersburg, MD). Briefly, XTT solution was prepared containing 0.3 $\mathrm{mg} / \mathrm{mL}$ XTT (2,3-bis(2-methoxy-4-nitro-5-sulfophenyl)-2H-tetrazolium-5- carboxanilide) and $20 \mu \mathrm{L} / \mathrm{mL}$ XTT Activator (phenazine methosulfate) diluted in DMEM. Cell culture media was then removed and replaced with the XTT solution and cells were incubated for 2 - 3 hours. Cell viability was quantified by the extent of soluble orange formazan dye formation by measuring absorbance at a wavelength of $490 \mathrm{~nm}$ and a reference of $650 \mathrm{~nm}$ on BioTek Synergy 2 colorimetric plate reader using Gen5 version 1.05 (BioTek, Winooski, VT). Statistical analysis and $\mathrm{IC}_{50}$ calculations were performed using GraphPad Prism software (GraphPad Software, Inc., San Diego CA). Error bars represent 95\% confidence intervals (CI).

\subsection{Time Course and Bright-Field Microscopy}

SiHa cells-cultured in 96 well tissue culture plates-were treated with sanguinarine, recombinant TRAIL, or a combination of the two and subjected to bright-field microscopy (Olympus IX70 microscope, 40× magnification) prior to performing XTT cell viability assays.

\subsection{Caspase 3/7 Assay}

SiHa cells were seeded onto a 96-well plate as described previously at a density of 5000 cells per well. After 24 hours of incubation, cells were treated with sanguinarine $(1.0 \mu \mathrm{M})$, TRAIL $(250 \mathrm{ng} / \mathrm{mL})$, or a combination of TRAIL-sanguinarine and incubated for 24 hours. Induction of apoptosis was assessed by measuring the activity of caspase-3/7 using the SonsoLyte Homogenous AMC Caspase-3/7 Assay Kit (AnaSpec, Fremont, CA). Caspase-3/7 substrate solution was added to each well and incubated in the dark at room temperature for 1 hour with gentle shaking. Active caspases 3/7 from apoptotic cells cleave the peptide substrate Asp-Glu-ValAsp (DEVD) provided in the assay kit to release the fluorophore Amino-4-methylcoumarin (AMC). Following incubation, fluorescence emitted from the sample was measured at $440 \mathrm{~nm}$ post-excitation at $360 \mathrm{~nm}$ using a BioTek Synergy 2 plate reader. Gen5 software (version 1.05) was used for data acquisition and data analysis was performed with GraphPad Prism software.

\subsection{Reactive Oxygen Species Assay}

DCFDA Cellular Reactive Oxygen Species Detection Assay Kit (Abcam Cambridge, MA) was used to quantify the levels of reactive oxygen species (ROS). Briefly, the assay uses the fluorophore DCFDA (2',7'-dichlorofluorescin diacetate), which diffuses into cells and is deacetylated by cellular esterases into a non-fluorescent compound. Upon exposure to reactive oxygen species such as superoxide and hydroperoxyl radicals, DCFDA is oxidized into 2',7'-dichlorofluorescein (DCF) -a fluorescent compound. SiHa cells, cultured in 96 well plates, were incubated with DCFDA for 45 minutes. After washing the wells with PBS, cells were treated with either tert-butyl hydrogen peroxide (TBHP, as a positive control) or varying concentrations of sanguinarine $(1.5$ to $0.75 \mu \mathrm{M})$ and incubated for 8 
hours. Fluorescence (excitation/emission of $485 / 540 \mathrm{~nm}$ ) was measured using the BioTek Synergy 2 and data analysis was performed using GraphPad Prism software as described earlier.

\subsection{Flow Cytometry Analysis of Death Receptor Expression}

$\mathrm{SiHa}$ cells were plated onto 6-well plates at 100,000 cells per well. After one day, cells were treated with $1 \mu \mathrm{M}$ sanguinarine for either 6 or 12 hours. Following treatment, cells were harvested using Cell Stripper (VWR, Westchester, PA), a non-enzymatic cell dissociation reagent. Cells floating in the media before harvest and those that lifted off during washes with PBS were pooled with the harvested cells. The cells were first blocked with 1\% BSA in PBS and stained with either phycoerythrin labeled anti-DR4 (R\&D Systems, Minneapolis, MN) or anti-DR5 (Abcam, Cambridge, MA). Stained cells were analyzed for cell surface fluorescence using the FACSCaliber flow cytometry instrument (Becton-Dickinson, Franklin Lakes, NJ).

\section{Results and Discussion}

Cervical cancer is primarily caused by the human papilloma virus (HPV), which transforms normal cervical cells into cancerous cells that are highly resistant to radiation and chemotherapy. Induction of apoptosis in the transformed cells is a key strategy in successfully treating HPV-induced cervical cancer. TRAIL, through the binding and activation of death receptors DR4 and DR5, has previously shown promise for the targeted induction of apoptotic pathways in cancer cells [12] [15] [17] [18] [27] [28] [29]. However, certain cancer cells such as the HPV16 infected cervical cancer SiHa cell line are not responsive to TRAIL-mediated induction of apoptosis [12] [17]. Since sanguinarine has proven to be effective in sensitizing human gastric adenocarcinoma (AGS) and human breast adenocarcinoma (MDA-231) to TRAIL [22] [23], we investigated the efficacy of a TRAIL-sanguinarine treatment combination for its ability to show similar effects on cancers caused by HPV infection using the SiHa cell line

Changes in the viability of SiHa cells following exposure to sanguinarine or TRAIL exposure were assessed by a dose response study (Figure 1). Sanguinarine was found to have an $\mathrm{IC}_{50}$ of approximately $1.75 \mu \mathrm{M}$ with a fairly narrow partially-therapeutic range (Figure 1(a)). When exposed to TRAIL in a range of concentrations (100 to $250 \mathrm{ng} / \mathrm{mL}$ ) that typically induce cell death in several other cancer cells [16], SiHa cells showed no significant changes in cell viability as compared to untreated cells (Figure 1(b)) - a finding consistent with previous observations [12] [17] [18] [24] [26] [27].

SiHa cells were next treated with a combination of sanguinarine and TRAIL (Figure 2). A sub-lethal dose of $1.0 \mu \mathrm{M}$ sanguinarine-a concentration lower than the $\mathrm{IC}_{50}$-was used in combination with TRAIL (100 or $250 \mathrm{ng} / \mathrm{mL}$ ). As compared to SiHa cells treated with either sanguinarine or TRAIL alone, combination treatments showed a significant decrease in cell viability (Figure 2). Furthermore, the decrease in cell viability in the combination treatments was 


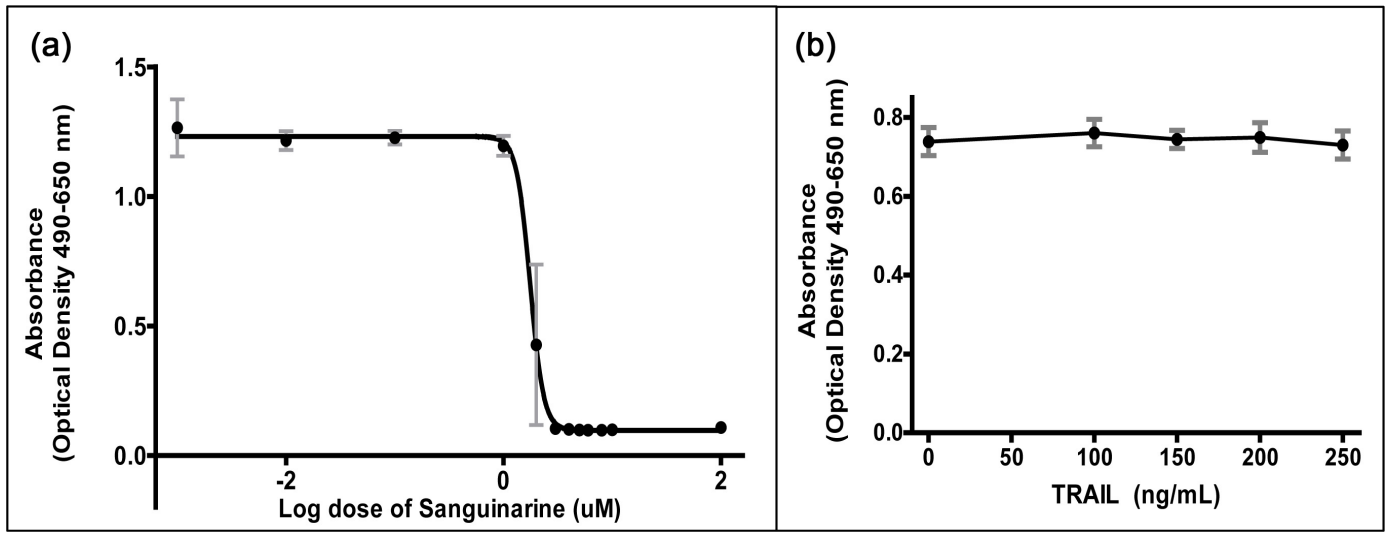

Figure 1. Concentration-response curves for SiHa cells treated with sanguinarine or TRAIL. (a) Effect of sanguinarine at concentrations ranging from $0.001 \mathrm{uM}$ to $100 \mathrm{uM}$ on the viability of SiHa cells. The $\mathrm{IC}_{50}$ was calculated to be $1.75 \pm 0.12 \mu \mathrm{M}$; (b) Effect of TRAIL at concentrations ranging from 100 to $250 \mathrm{ng} / \mathrm{mL}$ on the viability of $\mathrm{SiHa}$ cells. The $\mathrm{IC}_{50}$ could not be estimated since no significant changes in cell viability were observed as compared to untreated cells. Data shown is representative of triplicate experiments for both (a) and (b). Error bars denote 95\% CI.

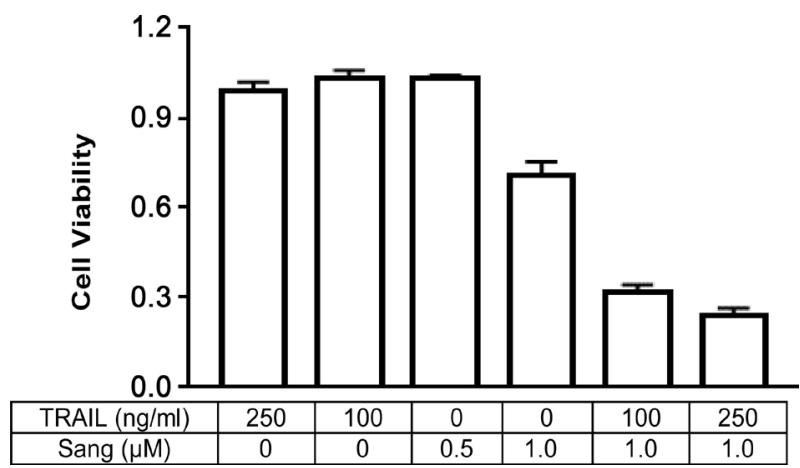

Figure 2. Viability of SiHa cells following 24-hour treatment with either TRAIL, sanguinarine (Sang), or a combination of the two as shown in the table for the X-axis. Y-axis indicates absorbance data normalized to untreated cells from XTT cell viability assays. Error bars indicate standard deviation $(\mathrm{N}=4)$.

dependent on the dose of TRAIL; marginally lower cell viability was observed with $250 \mathrm{ng} / \mathrm{ml}$ of TRAIL as compared to $100 \mathrm{ng} / \mathrm{ml}$ (Figure 2). These observations suggest that sanguinarine can indeed sensitize SiHa cells to TRAIL leading to a significant reduction in cell viability.

A time course experiment was next performed with the sanguinarine and TRAIL combination treatment of SiHa cells. As compared to SiHa cells treated with either sanguinarine or TRAIL alone, combination treatments showed a significant decrease in cell viability after 6 hours of treatment (Figure 3(a)). At 12 hours post-treatment, cell viability-as determined by XTT assays-decreased by $75 \%$. Morphological changes in cells were also tracked by bright-field microscopy during the time course treatments. While $\mathrm{SiHa}$ cells treated with either sanguinarine or TRAIL alone did not appear significantly different in from untreated cells (Figure 3(b)), cells exposed to the combination treatment exhibited distinct morphological changes. Starting from about 6 hours post-treatment, cells appear rounded with marked blebbing. These features suggest the likelih- 
ood of an induction of apoptosis resulting from the TRAIL-sanguinarine combination treatments (Figure 3(c)).

Activation of the caspase cascade is a distinct feature of the induction of apoptosis. To confirm cell-death from apoptosis following TRAIL-sanguinarine treatment, the enzymatic activities of caspase- 3 and caspase-7 were analyzed.

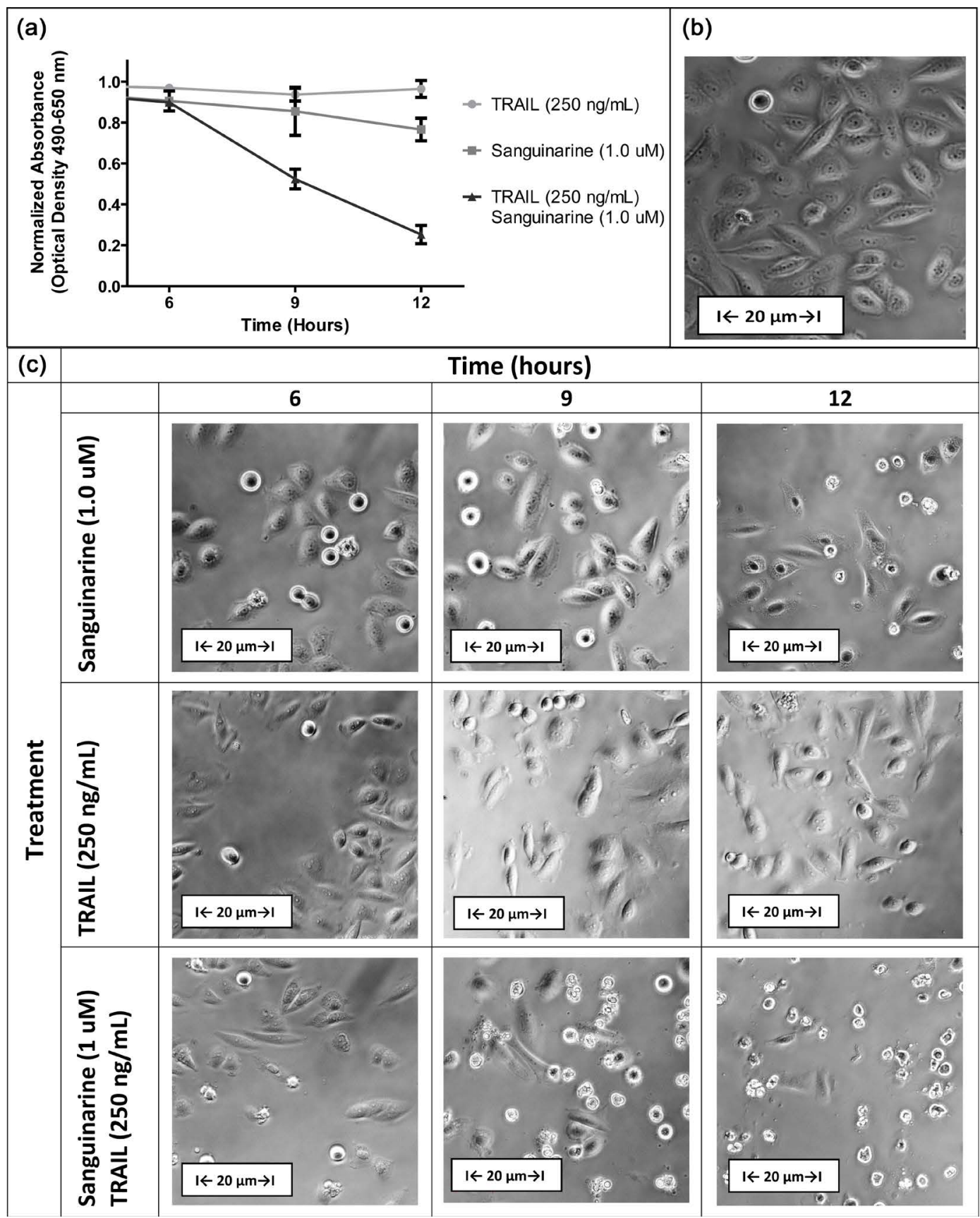

Figure 3. (a) Time course changes in the viability of SiHa cells treated with either TRAIL (250 ng/Ml), sanguinarine $(1.0 \mu \mathrm{M})$, or combination of the two. Y-axis indicates XTT cell viability assay absorbance data normalized to untreated cells. Error bars represent $95 \%$ confidence intervals $(\mathrm{N}=4)$; (b) Bright-field microscopy image of untreated SiHa cells; (c) Representative images from bright-field microscopy show changes in SiHa cell morphology following treatment with either TRAIL (250 ng/Ml), sanguinarine (1.0 $\mu \mathrm{M})$, or combination of the two. 


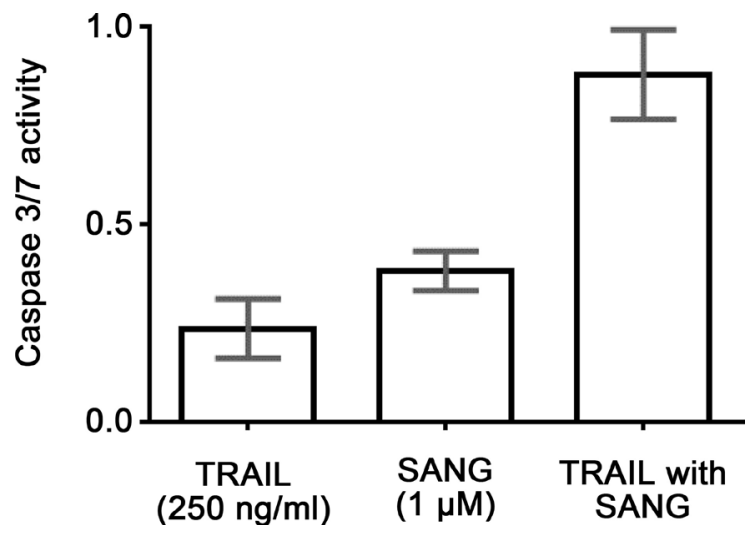

Figure 4. Activation of caspase 3/7. SiHa culture cells were treated with either TRAIL $(250 \mathrm{ng} / \mathrm{mL})$, sanguinarine $(1.0 \mu \mathrm{M})$, or a combination (TRAIL with sanguinarine) of the two for 24 hours. Enzymatic activities of caspase 3 and 7 were measured using a fluorogenic substrate. Numbers on the Y-axis indicate normalized fluorescence values for the treated $\mathrm{SiHa}$ cells. Error bars represent standard deviation $(\mathrm{N}=5)$.

Cells treated with TRAIL or sanguinarine alone showed only a marginal increase in the activity of caspases 3 and 7 (Figure 4). However, SiHa cells that were treated with the combination of TRAIL-sanguinarine showed a significant increase in caspase 3/7 activities (Figure 4). These results clearly show that TRAIL and sanguinarine act synergistically to induce a caspase cascade leading to cell death in SiHa cells by apoptosis.

We next designed experiments to understand the molecular mechanism of sanguinarine-mediated sensitization of SiHA cells to TRAIL. Previous work suggests that sanguinarine treatment can induce oxidative stress and lead to the upregulation of TRAIL receptors [24] [25] [26]. To investigate this phenomenon, we treated $\mathrm{SiHa}$ cells with sanguinarine and analyzed the production of reactive oxygen species. A substantial increase in reactive oxygen species was observed in $\mathrm{SiHa}$ cells treated with a range of sanguinarine concentrations from 0.75 to $1.5 \mu \mathrm{M}$. The level of oxidative stress was comparable to treatments with tert-butyl hydrogen peroxide (TBHP) - a known oxidizer that was used as a positive control for these experiments. Although oxidative stress was clearly observed in all experiments following treatments with sub-lethal doses of sanguinarine, it is important to note that the extent of oxidative stress observed in $\mathrm{SiHa}$ cells showed considerable variations from one experiment to the other. Data presented in the graph on Figure 5(a) is representative of one set of experiments.

Along with the induction of oxidative stress, sanguinarine is known to cause the upregulation of receptors for TRAIL, in particular DR5 [24]. TRAIL is known to interact with four receptors: DcR1, DcR2, DR4 and DR5. The receptors DcR1 and DcR2 act as "decoy receptors" that do not trigger apoptosis following TRAIL binding. DR4 and DR5 act as "functional death receptors" that become active when TRAIL binds to and initiates trimerization of the receptors, activating apoptotic pathways [15] [16] [30] [31] [32]. For this reason, cell surface expression of DR4 and DR5 is important for TRAIL-mediated apoptosis. We performed flow cytometry in an attempt to assess changes of DR4 and DR5 

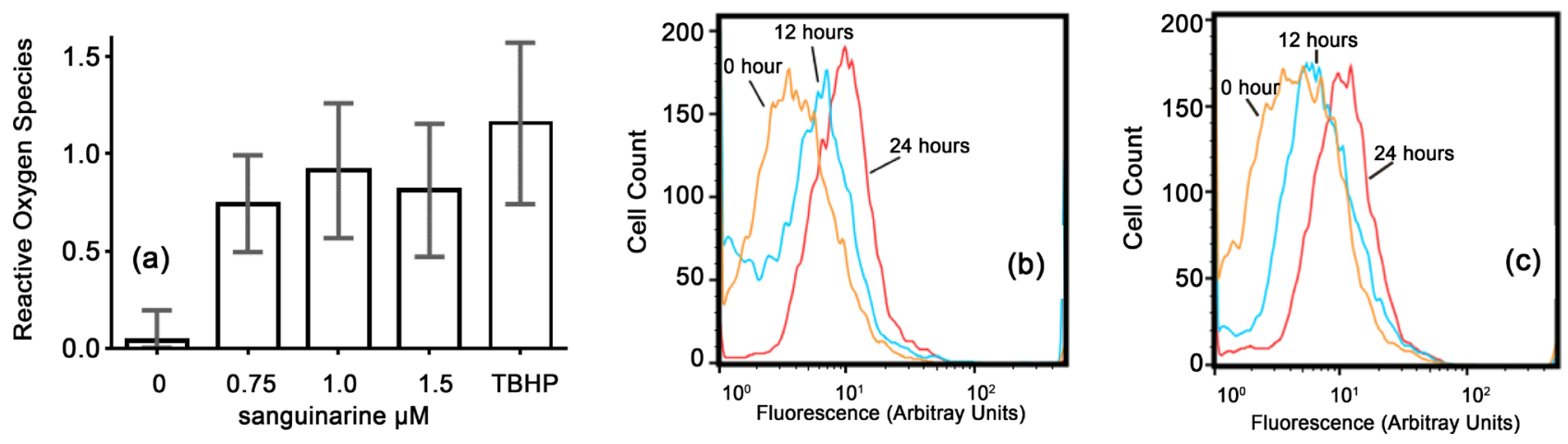

Figure 5. Oxidative stress and expression of death receptors following sanguinarine treatment. (a) SiHa cells were treated with sub-lethal doses of sanguinarine and the production of reactive oxygen species was quantified. Numbers on the Y-axis indicate relative fluorescence units and corresponds to the level of reactive oxygen species. Tertbutyl hydrogen peroxide (TBHP) was used as a positive control to induce oxidative stress. All experiments were carried out in triplicates and error bars represent standard deviation of the mean; (b) Flow cytometry analysis of death receptor DR4 expression on the surface of SiHa cells following treatment with $1 \mu \mathrm{M}$ sanguinarine; (c) Flow cytometry analysis of death receptor DR5 expression on the surface of SiHa cells following treatment with $1 \mu \mathrm{M}$ sanguinarine.

exposure of SiHa cells to sanguinarine at different time points (Figure $5(\mathrm{~b})$ and Figure 5(c)). Interestingly, changes in the cell-surface expression of DR4 and DR5 appeared to be highly variable from one experiment to the other. While higher death receptor expression was observed in most experiments, the quantitative changes observed were not reproducible. Based on previous studies, we speculate that DR4 and DR5 upregulation is most likely to be mediated by oxidative stress resulting from sanguinarine exposure [24]. Hence the lack of reproducibility with the extent of DR4 and DR5 upregulation may be linked to the inconsistent increases in the increased levels of reactive oxygen species following sanguinarine treatment of SiHa cells. However, observations presented here from two separate experiments clearly indicate the potential of sanguinarine to upregulate these two death receptors in SiHa cells (Figure 5(b) and Figure $5(c))$. An increase in the expression of death receptors then allows TRAIL to bind to SiHa cells and induce cell death by triggering apoptosis pathways.

\section{Conclusion}

Results from this study suggest that sanguinarine can sensitize cervical cancer $\mathrm{SiHa}$ cells to TRAIL leading to cell death by apoptosis. Although preliminary, our data indicate that oxidative stress leading to the upregulation of death receptors DR4 and DR5 seems to play a central role in this synergy between sanguinarine and TRAIL. While the molecular pathways linking reactive oxygen species and the possible upregulation of death receptors needs further investigation-both in cell culture as well as animal models-the observed synergistic effect of sanguinarine and TRAIL on SiHa cells is promising for the treatment of cervical, and possibly other, HPV-induced cancers.

\section{Acknowledgements}

Anjali Taneja, Bernardo Chavira and Aaron Mody for technical help with expe- 
riments, data analysis and manuscript preparation.

\section{References}

[1] American Cancer Society. (2015) Global Cancer Facts \& Figures. 3rd Edition, American Cancer Society, Atlanta.

[2] Siegel, R.L., Miller, K.D., and Jemal, A. (2015) Cancer Statistics, 2015. CA: A Cancer Journal for Clinicians, 65, 5-29. https://doi.org/10.3322/caac.21254

[3] Fitzmaurice, C., Dicker, D., Pain, A., et al. (2015) The Global Burden of Cancer 2013. JAMA Oncology, 1, 505-527. https://doi.org/10.1001/jamaoncol.2015.0735

[4] Walboomers, J.M., Jacobs, M.V., Manos, M.M., et al. (1999) Human Papillomavirus Is a Necessary Cause of Invasive Cervical Cancer Worldwide. The Journal of Pathology, 189, 12-19. https://doi.org/10.1002/(sici)1096-9896(199909)189:1<12::aid-path431>3.0.c0;2-f

[5] Ghittoni, R., Accardi, R., Chiocca, S., et al. (2015) Role of Human Papillomaviruses in Carcinogenesis. Ecancer Medical Science, 9, 526. https://doi.org/10.3332/ecancer.2015.526

[6] Bell, M.C. and Alvarez, R.D. (2005) Chemoprevention and Vaccines: A Review of the Nonsurgical Options for the Treatment of Cervical Dysplasia. International Journal of Gynecological Cancer, 15, 4-12. https://doi.org/10.1111/j.1048-891X.2005.15002.x

[7] Govan, V.A. (2008) A Novel Vaccine for Cervical Cancer: Quadrivalent Human Papillomavirus (Types 6, 11, 16 and 18) Recombinant Vaccine (Gardasil). Therapeutics and Clinical Risk Management, 4, 65-70. https://doi.org/10.2147/TCRM.S856

[8] Vale, C.L. (2010) Reducing Uncertainties about the Effects of Chemoradiotherapy for Cervical Cancer: Individual Patient Data Meta-Analysis.

http://onlinelibrary.wiley.com/doi/10.1002/14651858.CD008285/abstract

[9] Kim, Y.S., Shin, S.S., Nam, J.H., et al. (2008) Prospective Randomized Comparison of Monthly Fluorouracil and Cisplatin Versus Weekly Cisplatin Concurrent with Pelvic Radiotherapy and High-Dose Rate Brachytherapy for Locally Advanced Cervical Cancer. Gynecologic Oncology, 108, 195-200.

https://doi.org/10.1016/j.ygyno.2007.09.022

[10] Ang, K.K. (2005) Concurrent Radiation Chemotherapy for Locally Advanced Head and Neck Carcinoma: Are We Addressing Burning Subjects? Journal of Clinical Oncology, 23, 248.

[11] Lapresa, M., Parma, G., Portuesi, R., et al. (2015) Neoadjuvant Chemotherapy in Cervical Cancer: An Update. Expert Review of Anticancer Therapy, 15, 1171-1181. https://doi.org/10.1586/14737140.2015.1079777

[12] Eaton, S., Wiktor, P., Thirstrup, D., et al. (2011) Efficacy of Trail Treatment against Hpv16 Infected Cervical Cancer Cells Undergoing Senescence Following Sirna Knockdown of E6/E7 Genes. Biochemical and Biophysical Research Communications, 405, 1-6. https://doi.org/10.1016/j.bbrc.2010.12.056

[13] Hao, Z., Han, X., Sun, X., et al. (2016) Fully Human Monoclonal Antibodies to Trail-R1 Enhance Trail-Induced Apoptosis via Activation of Caspase-8 Pathway. Biochemical and Biophysical Research Communications, 475, 238-244. https://doi.org/10.1016/j.bbrc.2016.05.089

[14] Kiraz, Y., Adan, A., Kartal Yandim, M., et al. (2016) Major Apoptotic Mechanisms and Genes Involved in Apoptosis. Tumor Biology, 37, 8471-8486. https://doi.org/10.1007/s13277-016-5035-9 
[15] Reesink-Peters, N., Hougardy, B.M., van den Heuvel, F.A., et al. (2005) Death Receptors and Ligands in Cervical Carcinogenesis: An Immunohistochemical Study. Gynecologic Oncology, 96, 705-713. https://doi.org/10.1016/j.ygyno.2004.10.046

[16] de Miguel, D., Lemke, J., Anel, A., et al. (2016) Onto Better Trails for Cancer Treatment. Cell Death and Differentiation, 23, 733-747. https://doi.org/10.1038/cdd.2015.174

[17] Hougardy, B.M., Maduro, J.H., van der Zee, A.G., et al. (2006) Proteasome Inhibitor Mg132 Sensitizes Hpv-Positive Human Cervical Cancer Cells to Rhtrail-Induced Apoptosis. International Journal of Cancer, 118, 1892-1900. https://doi.org/10.1002/ijc. 21580

[18] Lemke, J., von Karstedt, S., Zinngrebe, J., et al. (2014) Getting Trail Back on Track for Cancer Therapy. Cell Death and Differentiation, 21, 1350-1364. https://doi.org/10.1038/cdd.2014.81

[19] Micheau, O., Shirley, S. and Dufour, F. (2013) Death Receptors as Targets in Cancer. British Journal of Pharmacology, 169, 1723-1744. https://doi.org/10.1111/bph.12238

[20] Herbst, R.S., Eckhardt, S.G., Kurzrock, R., et al. (2010) Phase I Dose-Escalation Study of Recombinant Human Apo21/Trail, a Dual Proapoptotic Receptor Agonist, in Patients with Advanced Cancer. Journal of Clinical Oncology, 28, 2839-2846. https://doi.org/10.1200/JCO.2009.25.1991

[21] Soria, J.C., Smit, E., Khayat, D., et al. (2010) Phase 1b Study of Dulanermin (Recombinant Human Apo21/Trail) in Combination with Paclitaxel, Carboplatin, and Bevacizumab in Patients with Advanced Non-Squamous Non-Small-Cell Lung Cancer. Journal of Clinical Oncology, 28, 1527-1533. https://doi.org/10.1200/JCO.2009.25.4847

[22] Choi, W.Y., Jin, C.Y., Han, M.H., et al. (2009) Sanguinarine Sensitizes Human Gastric Adenocarcinoma Ags Cells to Trail-Mediated Apoptosis via Down-Regulation of Akt and Activation of Caspase-3. Anticancer Research, 29, 4457-4465. http://ar.iiarjournals.org/content/29/11/4457.long

[23] Kim, S., Lee, T.J., Leem, J., et al. (2008) Sanguinarine-Induced Apoptosis: Generation of Ros, Down-Regulation of Bcl-2, C-Flip, and Synergy with Trail. Journal of Cellular Biochemistry, 104, 895-907. https://doi.org/10.1002/jcb.21672

[24] Hussain, A.R., Al-Jomah, N.A., Siraj, A.K., et al. (2007) Sanguinarine-Dependent Induction of Apoptosis in Primary Effusion Lymphoma Cells. Cancer Research, 67, 3888-3897. https://doi.org/10.1158/0008-5472.CAN-06-3764

[25] Ahmad, N., Gupta, S., Husain, M.M., et al. (2000) Differential Antiproliferative and Apoptotic Response of Sanguinarine for Cancer Cells Versus Normal Cells. Clinical Cancer Research, 6, 1524-1528.

http://clincancerres.aacrjournals.org/content/6/4/1524.long

[26] Xu, J.Y., Meng, Q.H., Chong, Y., et al. (2012) Sanguinarine Inhibits Growth of Human Cervical Cancer Cells through the Induction of Apoptosis. Oncology Reports, 28, 2264-2270.

[27] Lum, J.J., Pilon, A.A., Sanchez-Dardon, J., et al. (2001) Induction of Cell Death in Human Immunodeficiency Virus-Infected Macrophages and Resting Memory Cd4 T Cells by Trail/Apo2l. Journal of Virology, 75, 11128-11136. https://doi.org/10.1128/JVI.75.22.11128-11136.2001

[28] Shivapurkar, N., Toyooka, S., Toyooka, K.O., et al. (2004) Aberrant Methylation of Trail Decoy Receptor Genes Is Frequent in Multiple Tumor Types. International Journal of Cancer, 109, 786-792. https://doi.org/10.1002/ijc.20041 
[29] Spierings, D.C., de Vries, E.G., Vellenga, E., et al. (2004) Tissue Distribution of the Death Ligand Trail and Its Receptors. Journal of Histochemistry and Cytochemistry, 52, 821-831. https://doi.org/10.1369/jhc.3A6112.2004

[30] Nimmanapalli, R., Perkins, C.L., Orlando, M., et al. (2001) Pretreatment with Paclitaxel Enhances Apo-2 Ligand/Tumor Necrosis Factor-Related Apoptosis-Inducing Ligand-Induced Apoptosis of Prostate Cancer Cells by Inducing Death Receptors 4 and 5 Protein Levels. Cancer Research, 61, 759-763. http://cancerres.aacrjournals.org/content/61/2/759.long

[31] Wang, D., Upadhyaya, B., Liu, Y., et al. (2014) Phenethyl Isothiocyanate Upregulates Death Receptors 4 and 5 and Inhibits Proliferation in Human Cancer Stem-Like Cells. BMC Cancer, 14, 591. https://doi.org/10.1186/1471-2407-14-591

[32] Kim, H., Kim, E.H., Eom, Y.W., et al. (2006) Sulforaphane Sensitizes Tumor Necrosis Factor-Related Apoptosis-Inducing Ligand (Trail)-Resistant Hepatoma Cells to Trail-Induced Apoptosis through Reactive Oxygen Species-Mediated Up-Regulation of Dr5. Cancer Research, 66, 1740-1750.

https://doi.org/10.1158/0008-5472.CAN-05-1568

Submit or recommend next manuscript to SCIRP and we will provide best service for you:

Accepting pre-submission inquiries through Email, Facebook, LinkedIn, Twitter, etc. A wide selection of journals (inclusive of 9 subjects, more than 200 journals)

Providing 24-hour high-quality service

User-friendly online submission system

Fair and swift peer-review system

Efficient typesetting and proofreading procedure

Display of the result of downloads and visits, as well as the number of cited articles

Maximum dissemination of your research work

Submit your manuscript at: http://papersubmission.scirp.org/

Orcontact jct@scirp.org 